NBER WORKING PAPER SERIES

\title{
MANAGERIAL VALUE DIVERSION AND SHAREHOLDER WEALTH
}

\author{
Lucian Arye Bebchuk \\ Christine Jolls
}

Working Paper 6919

http://www.nber.org/papers/w6919

\author{
NATIONAL BUREAU OF ECONOMIC RESEARCH \\ 1050 Massachusetts Avenue \\ Cambridge, MA 02138 \\ February 1999
}

The authors thank Rishi Ganti, Paul Joskow, Louis Kaplow, Tracy Lewis, Mark Liffman, James Poterba, Alan Schwartz, Eric Talley, and two anonymous referees for helpful comments. Financial support from the John M. Olin Center for Law, Economics, and Business and the National Science Foundation (Bebchuk) and from the National Science Foundation Graduate Fellowship Program (Jolls) is gratefully acknowledged. The views expressed here are those of the author and do not reflect those of the National Bureau of Economic Research.

(c) 1999 by Lucian Arye Bebchuk and Christine Jolls. All rights reserved. Short sections of text, not to exceed two paragraphs, may be quoted without explicit permission provided that full credit, including $\left.{ }^{(}\right)$ notice, is given to the source. 
Managerial Value Diversion and Shareholder Wealth

Lucian Arye Bebchuk and Christine Jolls

NBER Working Paper No. 6919

February 1999

JEL No. K22, G34, G38

\section{ABSTRACT}

The agents to whom shareholders delegate the management of corporate affairs may transfer value from shareholders to themselves through a variety of mechanisms, such as self-dealing, insider trading, and taking of corporate opportunities. A common view in the law and economics literature is that such value diversion does not ultimately produce a reduction in shareholder wealth, since value diversion simply substitutes for alternative forms of compensation that would otherwise be paid to managers. We question this view within its own analytical framework by studying, in a principal-agent model, the effects of allowing value diversion on managerial compensation and effort. We suggest that the standard law and economics view of value diversion overlooks a significant cost of such behavior. Many common modes of compensation can provide managers with incentives to enhance shareholder value; replacing such compensation would reduce these incentives. As a result, even if the consequences of a rule permitting value diversion can be fully taken into account in settling managerial compensation, such a rule might still produce a reduction in shareholder wealth -- and would not do so only if value diversion would have some countervailing positive effects (a possibility which our model considers) that are sufficiently significant in size.

Lucian Arye Bebchuk

Harvard Law School

Cambridge, MA 02138

and NBER

bebchuk@law.harvard.edu
Christine Jolls

Harvard Law School

Cambridge, MA 02138

and NBER

jolls@law.harvard.edu 


\section{INTRODUCTION}

The agents to whom shareholders delegate the management of the typical large corporation have a variety of opportunities to transfer value from shareholders to themselves. These agents may take business opportunities presented to the firm and turn them to their own advantage; they may engage in classic self-dealing, selling assets to the firm or buying assets from it at non-arms'-length prices; they may trade in the firm's stock on the basis of inside information; or they may provide themselves with various perks not germane to their job responsibilities. Each of these actions provides managers with private benefits that increase the effective level of managerial pay above the level implied by salaries, bonuses, and other forms of direct compensation.

Much of corporate law is addressed to the problem of managerial value diversion in its various incarnations. State and federal rules curtail or regulate the taking of corporate opportunities, transactions between corporations and their managers, insider trading, and the provision of perks and other benefits to managers (Clark, 1986: 166-79, 191-94, 225-30, 293340). These legal rules reflect a background presumption that value diversion harms shareholders and should be discouraged. On this view, value diversion is undesirable (and appropriately curtailed by legal rules) absent some reason to believe that such behavior produces offsetting gains for shareholders.

A common view in the law and economics literature is that the traditional presumption against managerial value diversion is misguided (Manne, 1966; Manne, 1970; Scott, 1980; Easterbrook and Fischel, 1982; Carlton and Fischel, 1983; Haddock and Macey, 1987; Easterbrook and Fischel, 1991). Many of these authors have argued that value diversion does not raise the distributional and fairness concerns that underlie the traditional disapproval of such 
behavior because value diversion is simply an alternative form of managerial compensation, a substitute for salaries, bonuses, and other forms of direct managerial pay. Benefits from value diversion will be offset by reductions in direct compensation, leaving total managerial pay and the total wealth enjoyed by shareholders unchanged (Easterbrook and Fischel, 1982: 707, 73435; Haddock and Macey, 1987: 1461-62). Value diversion no more hurts shareholders than does payment of salaries, bonuses, and other familiar forms of compensation. Consequently, shareholders have no need for the protective (restrictive) legal rules imposed by current law.

One objection to this benign view of value diversion is that the process by which managers' direct compensation is set does not conform to the hypothetical ideal envisioned by the view's proponents. It may be implausible to assume, as those proponents do, that the level of managerial pay is set by a disinterested agent seeking to maximize share value (Brudney, 1985). The board of directors of the typical large corporation may be partial to managers' interests and therefore reluctant to pursue an aggressive strategy of lowering salaries and other forms of direct compensation in response to managers' ability to divert value from shareholders (a form of transfer that will often occur without shareholders' knowledge). Legal restrictions on value diversion may then be a pragmatic response to the consequences of value diversion in real-world settings.

This paper offers a different objection to the benign view of value diversion. We reexamine that view within its own analytical framework by studying, in a principal-agent model, the effects of allowing value diversion on managerial compensation and managerial effort. Our analysis suggests that the benign view of value diversion overlooks a significant cost of such behavior. This cost justifies the conclusion that value diversion is undesirable unless it produces sufficiently large countervailing benefits. 
The cost of value diversion on which we focus results from the relationship between managerial compensation and incentives in a principal-agent setting. The compensation paid to managers in such a setting will typically depend significantly on firm performance. Bonuses, stock options, and other forms of performance-based pay tie managers' fate to shareholders' return. Against this backdrop, reducing managers' compensation to adjust for opportunities for value diversion will mean reducing the alignment of shareholders' and managers' interests. Shareholders are effectively faced with a catch-22: either they reduce managers' compensation in response to opportunities for value diversion and bear the resulting costs of weakened incentives, or they leave compensation alone and enjoy no offsetting adjustment in compensation in response to value diversion.

The dilemma confronting shareholders in this setting may be illustrated with a simple numerical example. Suppose that a manager would receive compensation with an expected value of $\$ 300,000$ in the absence of value diversion. Imagine that value diversion, if permitted, would impose costs of $\$ 200,000$ on shareholders and yield benefits of $\$ 200,000$ to the manager. (Value diversion here is a pure wealth transfer.) If shareholders respond to the prospect of value diversion by reducing the manager's direct compensation by $\$ 200,000$, then the manager's interests will be less aligned with those of shareholders (assuming that at least some portion of the original compensation package was performance-based). Share value will fall as a result. The adverse effect of adjusting compensation is reduced but not eliminated if direct compensation is decreased by some amount less than $\$ 200,000$ (say, $\$ 100,000$ ); the manager's incentives will still weaken, but by a smaller margin. However, to whatever extent the manager's direct compensation is not reduced by the full amount of the value diversion. shareholders will bear the costs of such behavior. Thus, no matter what response shareholders 
adopt, they will be worse off with value diversion than without it.

As this simple example illustrates, and as the analysis below shows, in the absence of some countervailing benefit, a rule permitting value diversion will generally reduce share value. Our analysis also models cases in which value diversion will have some beneficial effect on share value. If a particular form of value diversion produces countervailing benefits of a sufficient size, then a rule allowing such behavior may be desirable. But in such cases, our basic message still holds: permitting value diversion imposes a discrete cost on shareholders (one that may or may not be outweighed by countervailing benefits). Accordingly, a rule permitting value diversion will be desirable only if such behavior produces affirmative benefits that outweigh the cost we identify.

For expositive ease, we focus on two polar approaches to value diversion: absolute prohibition and absolute permission. This focus tracks the basic debate between those who support the existing legal regime (which prohibits value diversion except in narrowly defined circumstances) and those who argue that the law's restrictions on value diversion are misguided. Our conclusions, however, would be unaffected by a focus instead on the comparison between a restrictive (though not completely prohibitive) legal regime and a regime in which value diversion is permitted. (A separate comparison, which we do not perform, would be between a prohibitory regime and a regime that restricted, but did not prohibit, value diversion. We choose to focus our analysis on the choice between the existing (largely prohibitory) regime and a regime in which value diversion is permitted because these are the alternatives emphasized by the existing debate.) The fact that we are discussing possible legal regimes does place important limits on the sorts of schemes that may be used to regulate value diversion; schemes under which, for example, the permissibility of value diversion depends on a manager's past 
performance obviously could not be implemented as general legal rules.

In analyzing the effects on share value of prohibiting and permitting value diversion, we do not mean to suggest that all forms of value diversion could be successfully controlled by legal rules. Regulating certain forms of value diversion might involve substantial informational and enforcement costs, far greater than any conceivable benefit of a restrictive legal regime. Such forms of value diversion must effectively be taken for granted. In the case of other forms of value diversion, however, legal restrictions are feasible and, indeed, are commonly observed in practice. (Examples include restrictions on self-dealing and on the taking of corporate opportunities.) Of course, existing restrictions on value diversion may be too strict or not strict enough, and our analysis is motivated in part by the desire to shed light on that question.

Whatever the desired rule governing value diversion, there is the question of whether it should be a mandatory rule (one that individual firms cannot choose to opt out of) or a default rule. The general considerations that bear on the choice between mandatory and default rules have been the subject of much debate in the corporate law literature (Bebchuk, 1989a; Bebchuk, 1989b; Easterbrook and Fischel, 1989; Eisenberg, 1989; Gordon, 1989; Easterbrook and Fischel, 1991). We do not attempt to add to that debate here; our focus instead is on whether the substantive rule should be restrictive or permissive in its treatment of value diversion. ${ }^{.}$

Section I of the paper contains our basic model. In order to isolate the cost of value diversion that we identify, we assume in this model that diversion represents a pure wealth transfer between shareholders and managers. Section II discusses situations in which the cost

\footnotetext{
One familiar argument for allowing opting out is that the optimal treatment of a given issue, such as value diversion, may differ from firm to firm. Indeed, our analysis identifies how the optimal treatment of diversion ma: depend on certain firm-specific parameters and circumstances. At the same time, allowing opting out may involve costs; for example, it may create the problem of mid-stream opportunism emphasized by Bebchuk (1989a). In this paper we do not attempt to contribute to the existing literature on how to balance these competing factors.
} 
of value diversion may be offset by countervailing benefits. Section III concludes.

\section{BASIC MODEL: VALUE DIVERSION AS A PURE WEALTH TRANSFER}

\section{A. Framework}

The framework for our analysis is the standard principal-agent model, in which the profit earned by the principal (the shareholders of the firm) is a function of the level of effort exerted by the manager who runs the firm. The manager's effort level e is unobservable and, thus, subject to moral hazard. The firm's profit $\pi$ is "high" $(\pi=\bar{\pi})$ with probability $\mathrm{P}(\mathrm{e})$ and "low" $(\pi=\underline{\pi})$ with probability $1-\mathrm{P}(\mathrm{e})$, where $\mathrm{P}(\mathrm{e})$ is increasing and concave in $\mathrm{e}\left(\mathrm{P}^{\prime} \geq 0, \mathrm{P}^{\prime \prime}<0\right)$. (To ensure an interior solution, we also impose the technical conditions that $\lim _{\mathbf{e} \rightarrow-\infty} \mathrm{P}^{\prime}(\mathrm{e})=$ $\infty$ and $\lim _{\mathrm{e} \rightarrow-\infty}-\mathrm{P}^{\prime \prime}(\mathrm{e})<\infty$.) The manager is risk-neutral but wealth-constrained; in particular, we assume that the manager's pay must be at least $S_{0}$ whatever the firm's profit level. ${ }^{2}$ The manager has reservation wage $\mathrm{W}\left(>\mathrm{S}_{0}\right)$ and objective function

$$
P(e) \bar{I}+(1-P(e)) \underline{I}-e,
$$

where $\overline{\mathrm{I}}$ is the compensation paid to the manager when the firm's profit is high, I is the compensation paid to the manager when the firm's profit is low, and e is the cost of the manager's effort in dollar terms. We denote $\underline{I}$ by $S$; I may then be written as $S+\alpha \Delta_{\pi}$, where $\Delta_{\pi}$ is the difference between the high and low profit levels for the firm $\left(\Delta_{\pi}=\bar{\pi}-\underline{\pi}\right)$ and $\alpha$ is the manager's share of that difference. A managerial contract in our model is therefore a pair $(S, \alpha)$, where $S$ may be viewed as the manager's salary -- the amount paid to the manager regardless of how the firm does -- and $\alpha$ may be viewed as the profit-sharing component of the

\footnotetext{
Jolls (1995: ch. 3) considers the case of a non-wealth-constrained but risk-averse manager.
} 
compensation scheme or, equivalently, the degree to which the manager shares in the firm's gain in moving from low to high profit.

Our addition to the standard principal-agent framework is the prospect of value diversion by the manager. In our model, the manager not only influences the likelihood that the firm realizes the high profit level $(\bar{\pi})$ but also may enjoy some control over how much of the firm's profit actually finds its way into shareholders' hands. Specifically, we imagine that with probability $\theta(0<\theta<1)$ the manager is able to divert an amount $\mathrm{X}$ of the firm's profit. The probabilistic nature of the value diversion opportunity in our model reflects the characteristic uncertainty of gains from value diversion (Scott, 1980: 808). The transfer of X is a pure wealth transfer from shareholders to the manager; as noted above, we focus initially on this case to isolate the cost of permitting value diversion.

The normative perspective on which we focus is the perspective of maximizing ex ante share value. This is the perspective that those who set up a firm and take it public would adopt; they would want value diversion to be prohibited or permitted according to whether it decreased or increased the initial value of the firm. The focus on ex ante share value is consistent with the normative orientation of the existing law and economics literature on value diversion (see, for example, Easterbrook and Fischel, 1982). In Bebchuk and Jolls (1996), we analyze the effects of value diversion on the total wealth of the shareholder-manager unit and on the compensation received by the manager.

The first-best outcome in our model is achieved when the manager's effort level e maximizes the expected benefit of effort, $\mathrm{P}(\mathrm{e}) \bar{\pi}+(1-\mathrm{P}(\mathrm{e})) \underline{\pi}$, minus the cost of effort, e. We assume that the difference between the expected benefit and the expected cost of effort at the first-best effort level $\mathrm{e}^{\mathrm{FB}}$ is greater than or equal to the reservation wage $\mathrm{W}$ (formally, $\mathrm{P}\left(\mathrm{e}^{\mathrm{FB}}\right)^{-}$ 
$\left.+\left(1-\mathrm{P}\left(\mathrm{e}^{\mathrm{FB}}\right)\right) \underline{\pi}-\mathrm{e}^{\mathrm{FB}} \geq \mathrm{W}\right)$; otherwise hiring the manager could never be profitable. We further assume that the benefit-cost difference at the first-best effort level is greater than or equal to $\mathrm{W}$ $\mathrm{S}_{0}$ (formally, $\mathrm{P}\left(\mathrm{e}^{\mathrm{FB}}\right) \bar{\pi}+\left(1-\mathrm{P}\left(\mathrm{e}^{\mathrm{FB}}\right)\right) \underline{\pi}-\mathrm{e}^{\mathrm{FB}} \geq \mathrm{W}-\mathrm{S}_{0}$ ); this condition follows directly from the prior one if $\mathrm{S}_{0}$ (the minimum wealth level for the manager) is non-negative. In the first-best environment, the division of surplus between the shareholders and the manager is then determined by the levels of $S$ and $\alpha$.

In a second-best world, it is not possible to both ensure the choice of the first-best level of effort and maintain complete freedom to adjust the manager's salary and profit share as distributional considerations dictate. As a result of the link between managerial compensation and incentives, value diversion may have significant effects on ex ante share value.

\section{B. Optimal Managerial Contract When Value Diversion Is Prohibited}

When value diversion is prohibited, ex ante share value is the difference between the firm's expected profit, $\underline{\pi}+\mathrm{P}(\mathrm{e}) \Delta_{x}$, and the compensation owed to the manager. The contract design problem involves maximizing ex ante share value subject to incentive compatibility (IC), participation $(\mathrm{P})$, and minimum wealth (MW) constraints for the manager:

$$
\begin{gathered}
\max _{\mathrm{e}, \mathrm{S}, \alpha}\left\{\underline{\pi}+\mathrm{P}(\mathrm{e}) \Delta_{\pi}-\mathrm{S}-\mathrm{P}(\mathrm{e}) \alpha \Delta_{\pi}\right\} \\
\text { s.t. } \quad(\mathrm{IC}) \mathrm{e} \epsilon \operatorname{argmax}\left\{\mathrm{S}+\mathrm{P}(\mathrm{e}) \alpha \Delta_{x}-\mathrm{e}\right\} \\
\text { (P) } \mathrm{S}+\mathrm{P}(\mathrm{e}) \alpha \Delta_{\pi}-\mathrm{e} \geq \mathrm{W} ; \\
(\mathrm{MW}) \mathrm{S} \geq \mathrm{S}_{0} .
\end{gathered}
$$

Under standard technical conditions $\left(\lim _{\mathrm{e} \rightarrow-\infty} \mathrm{P}^{\prime}(\mathrm{e})=\infty\right.$ and $\left.\lim _{\mathrm{e} \rightarrow-\infty}-\mathrm{P}^{\prime \prime}(\mathrm{e})<\infty\right)$, a solution to this problem will involve a profit share $\alpha$ between 0 and 1 . In turn, $\alpha>0$ implies that the 
incentive compatibility constraint reduces to the first-order condition $\mathrm{P}^{\prime}(\mathrm{e}) \alpha \Delta_{\mathrm{x}}-1=0$, or, equivalently, $\mathrm{e}=\mathrm{e}(\alpha)$, where $\mathrm{e}(\alpha)$ is the effort level defined by the first-order condition. The problem in (1) therefore simplifies to

$$
\begin{gathered}
\max _{\mathrm{S}, \alpha}\left\{\underline{\pi}+\mathrm{P}(\mathrm{e}(\alpha)) \Delta_{\pi}-\mathrm{S}-\mathrm{P}(\mathrm{e}(\alpha)) \alpha \Delta_{\pi}\right\} \\
\text { s.t. } \quad \mathrm{S}+\mathrm{P}(\mathrm{e}(\alpha)) \alpha \Delta_{\pi}-\mathrm{e}(\alpha) \geq \mathrm{W} ; \\
\mathrm{S} \geq \mathrm{S}_{0} .
\end{gathered}
$$

The function $\mathrm{e}(\alpha)$ is increasing in $\alpha\left(\mathrm{de} / \mathrm{d} \alpha=-\mathrm{P}^{\prime}(\mathrm{e}(\alpha)) / \mathrm{P}^{\prime \prime}(\mathrm{e}(\alpha)) \alpha>0\right)$; intuitively, higher values of $\alpha$ increase the manager's payoff from working hard and, hence, increase the manager's optimal effort choice.

A managerial contract $(S, \alpha)$ that solves the problem in (2) must involve paying as much of the manager's compensation as possible in the form of profit sharing. Profit-based compensation encourages managerial effort, whereas straight salary payments do not. In our model, if the salary $S$ exceeded the minimum level $S_{0}$, then $S$ could be lowered, and $\alpha$ raised, without violating either the participation constraint or the minimum wealth constraint, and this change would increase ex ante share value. In turn, $S=S_{0}$ implies that the optimal profit share $\alpha$ maximizes the objective function in (2) subject to the participation constraint. The participation constraint (with $S=S_{0}$ ) is satisfied for all $\alpha$ above a threshold value $\hat{\alpha}$ defined by

$$
\mathrm{S}_{0}+\mathrm{P}(\mathrm{e}(\hat{\alpha})) \hat{\alpha} \Delta_{\pi}-\mathrm{e}(\hat{\alpha})=\mathrm{W}
$$

It follows that the optimal share $\alpha$ is given by the unconstrained maximand $\alpha^{*}$ of the objective function in (2) if that value satisfies the participation constraint and by the minimum value that satisfies the participation constraint otherwise: 


$$
\left\{\begin{array}{ll}
\alpha^{*} & \text { if } \alpha^{*} \geq \hat{\alpha} \\
\hat{\alpha} & \text { otherwise }
\end{array}\right\}
$$

Thus, either the manager is paid more than the reservation wage to induce high effort $\left(\alpha=\alpha^{*}\right)$, or the manager's profit share is the minimum share permitted by the managerial participation constraint $(\alpha=\hat{\alpha})$.

\section{Optimal Managerial Contract When Value Diversion Is Permitted}

We now characterize the optimal managerial contract when value diversion is permitted. The contract design problem in that circumstance is:

$$
\begin{gathered}
\max _{\mathrm{e}, \mathrm{S}, \alpha}\left\{\underline{\pi}+\mathrm{P}(\mathrm{e}) \Delta_{\star}-\mathrm{S}-\mathrm{P}(\mathrm{e}) \alpha \Delta_{\pi}-\theta \mathrm{X}\right\} \\
\text { s.t. }(\mathrm{IC}) \mathrm{e} \epsilon \operatorname{argmax}\left\{\mathrm{S}+\mathrm{P}(\mathrm{e}) \alpha \Delta_{x}-\mathrm{e}+\theta \mathrm{X}\right\} \\
\text { (P) } \mathrm{S}+\mathrm{P}(\mathrm{e}) \alpha \Delta_{\pi}-\mathrm{e}+\theta \mathrm{X} \geq \mathrm{W} \\
(\mathrm{MW}) \mathrm{S} \geq \mathrm{S}_{0} .
\end{gathered}
$$

The only difference from the problem in (1) is that the shareholders now get $\theta \mathrm{X}$ less, and the manager $\theta \mathrm{X}$ more, on an expected basis. These differences in payoffs reflect the prospect of value diversion by the manager. Note that the minimum wealth constraint for the manager does not change; this is due to the fact that value diversion benefits are probabilistic and, thus, cannot help to satisfy the minimum wealth constraint.

Because the problem in (3) differs from the problem in (1) only by constant terms in the objective function and the incentive compatibility and managerial participation constraints. a solution to (3) must have $\mathrm{e}=\mathrm{e}(\alpha), \mathrm{S}=\mathrm{S}_{0}$, and $\alpha$ given by

$$
\left\{\begin{array}{ll}
\alpha^{*} & \text { if } \alpha^{*} \geq \tilde{\alpha} \\
\tilde{\alpha} & \text { otherwise }
\end{array}\right\},
$$


where $\bar{\alpha}$ is the minimum profit share permitted by the managerial participation constraint (with $\mathrm{e}=\mathrm{e}(\alpha)$ and $\mathrm{S}=\mathrm{S}_{0}$ ) when value diversion is permitted:

$$
\bar{\alpha}=\text { minimum } \alpha(\geq 0) \text { such that } \mathrm{S}_{0}+\mathrm{P}(\mathrm{e}(\alpha)) \alpha \Delta_{x}-\mathrm{e}(\alpha)+\theta \mathrm{X} \geq \mathrm{W} \text {. }
$$

The minimum profit share $\bar{\alpha}$ is less than the minimum profit share when value diversion is prohibited because the addition of $\theta \mathrm{X}$ to the manager's compensation when value diversion is permitted reduces the profit share needed to bring the manager up to the reservation wage W. Just as when value diversion is prohibited, the optimal managerial share must be non-negative, so if the minimum profit share $\bar{\alpha}$ is 0 , then the optimal managerial share must be $\alpha^{*}$.

\section{Effect of Value Diversion on Ex Ante Share Value}

Our characterization of the optimal managerial contract without and with value diversion permits us to assess the competing claims about value diversion and ex ante share value described in the introduction. Proposition 1 shows that value diversion necessarily reduces ex ante share value in a principal-agent framework when diversion operates as a pure wealth transfer from shareholders to managers.

Proposition 1: When value diversion is a pure wealth transfer, permitting such behavior reduces ex ante share value.

Proof: It is useful to distinguish three cases, based on the relationship between $\alpha^{*}, \hat{\alpha}$, and $\bar{\alpha}$. The cases considered below exhaust the set of possibilities because, as noted above, $\tilde{\alpha}<\hat{\alpha}$.

Case 1: $\alpha^{\cdot}<\tilde{\alpha}<\hat{\alpha}$. In this case the optimal managerial contract has $\alpha=\hat{\alpha}$ when value diversion is prohibited and $\alpha=\bar{\alpha}(>0$, since otherwise $\bar{\alpha}$ could not be optimal) when value diversion is permitted. Substituting from the managerial participation constraint, ex ante 
share value is $\underline{\pi}+\mathrm{P}(\mathrm{e}(\hat{\alpha})) \Delta_{\pi}-\mathrm{W}-\mathrm{e}(\hat{\alpha})$ when value diversion is prohibited and $\underline{\pi}+\mathrm{P}(\mathrm{e}(\tilde{\alpha})) \Delta_{\pi}$ $\mathrm{W}-\mathrm{e}(\tilde{\alpha})$ when value diversion is permitted. The change in ex ante share value with a move from forbidding to permitting value diversion is therefore given by

$$
\left[\mathrm{P}(\mathrm{e}(\tilde{\alpha})) \Delta_{x}-\mathrm{e}(\tilde{\alpha})\right]-\left[\mathrm{P}(\mathrm{e}(\hat{\alpha})) \Delta_{\pi}-\mathrm{e}(\hat{\alpha})\right]
$$

This expression is negative, as $\mathrm{e}(\tilde{\alpha})<\mathrm{e}(\hat{\alpha}), \mathrm{d}\left(\mathrm{P}(\mathrm{e}) \Delta_{\mathrm{x}}-\mathrm{e}\right) / \mathrm{de}>0$ for $\mathrm{e}<\mathrm{e}^{\mathrm{FB}}$, and $\mathrm{e}(\alpha)<\mathrm{e}^{\mathrm{FB}}$ for all $\alpha<1$, where $\mathrm{e}^{\mathrm{FB}}$ is the first-best effort level defined above. So ex ante share value is lower in the presence of value diversion than in its absence.

Case 2: $\tilde{\alpha} \leq \alpha^{*}<\hat{\alpha}$. Here the optimal managerial contract has $\alpha=\hat{\alpha}$ when value diversion is prohibited and $\alpha=\alpha^{*}$ when it is permitted. Ex ante share value is the same as in case 1 when value diversion is prohibited and (since the managerial participation constraint may be slack when value diversion is permitted) is less than or equal to $\underline{\pi}+\mathrm{P}\left(\mathrm{e}\left(\alpha^{*}\right)\right) \Delta_{\pi}-\mathrm{W}-\mathrm{e}\left(\alpha^{*}\right)$ when value diversion is permitted. The change in ex ante share value with a move from forbidding to permitting value diversion is therefore less than or equal to the difference in (4) with $\tilde{\alpha}=\alpha^{*}$. That difference is negative (as $\alpha^{*}<\hat{\alpha}$ ), so ex ante share value is again lower in the presence of value diversion than its absence.

Case 3: $\tilde{\alpha}<\hat{\alpha} \leq \alpha^{*}$. In this case the optimal managerial contract has $\alpha=\alpha^{*}$ when value diversion is prohibited and also when it is permitted. Since managerial compensation is not adjusted at all with a move from forbidding to permitting value diversion, ex ante share value falls by $\theta \mathrm{X}$ (the expected cost of value diversion to shareholders) with such a move.

Remarks: (1) Intuition. Proposition 1 shows that value diversion reduces ex ante share value in spite of shareholders' ability to adjust the manager's direct compensation in response. The 
intuition for this result is that adjusting managerial compensation to offset profits from value diversion imposes costs on shareholders due to the incentive effects of such adjustments. If direct compensation could be adjusted by lowering the manager's salary, then managerial incentives would not be affected. However, the manager's salary will already be at the minimum feasible level $\left(S_{0}\right)$ under an optimal managerial contract without value diversion; further decreases are not possible. Adjusting the manager's direct compensation therefore requires lowering the profit share $\alpha$, as occurs whenever $\alpha^{*}<\hat{\alpha}$ in our model (cases 1 and 2 above). Lowering the profit share lowers the level of effort that the manager will exert, which adversely affects ex ante share value. Lowering $\alpha$ may in fact be so costly that shareholders prefer not to do it; this is the case when $\alpha^{*} \geq \hat{\alpha}$ in our model (case 3 above). If $\alpha$ is not adjusted to offset profits from value diversion, then managerial incentives remain at their previous level, but ex ante share value falls by the full amount $\theta \mathrm{X}$ diverted by the manager.

(2) Possibility of "financing" of value diversion by manager. One might ask whether, in the presence of a rule permitting value diversion, the shareholders might respond by providing for a fixed salary of $S_{0}$ if the opportunity to divert value did not arise (an event with probability $1-\theta$ ) and a fixed salary of $S_{0}-X$ if the opportunity to divert value did arise (an event with probability $\theta$ ). In this case the effective level of guaranteed compensation would be $S_{0}$ whether or not value diversion turned out to be feasible; the situation would thus be no different from when value diversion is prohibited. (In particular, there would no longer be a need to distort $\alpha$ in response to the opportunity for value diversion.) This scenario amounts to managerial "financing" of the value diversion opportunity; the manager is "loaned" $\mathrm{X}$ by the firm and mus: repay it if but only if the opportunity for diversion arises.

To the extent that such financing is possible, shareholders may be able to avoid the 
incentive costs of value diversion identified by Proposition 1 by opting out of the unfavorable rule that permits such behavior. This possibility does not, however, make the choice between prohibiting and permitting value diversion irrelevant. The financing scheme requires an enforcement mechanism by which shareholders can determine whether value diversion has occurred. Such a mechanism will typically be very costly for shareholders of an individual firm to set up. Because there will often be substantial economies of scale in detecting value diversion (for instance, in the case of insider trading), a general legal rule is likely to be superior to firmby-firm enforcement.

\section{E. Magnitude of the Value Diversion Effect}

We now relate the magnitude of the fall in ex ante share value with value diversion to the amount of the firm's profit that the manager is able to divert.

Proposition 2: When value diversion is a pure wealth transfer, the reduction in ex ante share value with value diversion is an increasing function of the expected transfer $\theta \mathrm{X}$.

Proof: Suppose first that $\tilde{\alpha} \leq \alpha^{*}$ (cases 2 and 3 in the proof of proposition 1). An increase in $\theta \mathrm{X}$ then has no effect on the optimal managerial contract when value diversion is permitted, as the manager's profit share is already given by $\alpha^{*}$ rather than by the minimum share needed to satisfy the managerial participation constraint. An increase in $\theta X$ obviously has no effect on the optimal managerial contract when value diversion is prohibited, so the change in ex ante share value with a move from forbidding to permitting value diversion is

$$
\mathrm{P}\left(\mathrm{e}\left(\alpha^{*}\right)\right)\left(1-\alpha^{*}\right) \Delta_{\pi}-\theta \mathrm{X}-\mathrm{P}\left(\mathrm{e}\left(\hat{\alpha}^{\prime}\right)\right)\left(1-\hat{\alpha}^{\prime}\right) \Delta_{\pi} .
$$

where $\hat{\alpha}^{\prime}=\max \left\langle\alpha^{*}, \hat{\alpha}\right\rangle$ is the manager's profit share under an optimal managerial contract 
when value diversion is prohibited. It follows that as $\theta \mathrm{X}$ increases, the change in ex ante share value when value diversion is permitted falls (becomes more negative).

Suppose now that $\bar{\alpha}>\alpha^{*}$ (case 1 above); the managerial participation constraint now binds when value diversion is permitted, so increasing $\theta \mathrm{X}$ reduces the manager's profit share under an optimal managerial contract (either to a new value of $\tilde{\alpha}$ or to the unconstrained maximand $\alpha^{*}$ ). Substituting from the managerial participation constraint when value diversion is prohibited and when it is permitted, the change in ex ante share value with a move from forbidding to permitting value diversion is less than or equal to

$$
\left[\mathrm{P}\left(\mathrm{e}\left(\tilde{\alpha}^{\prime}\right)\right) \Delta_{x}-\mathrm{e}\left(\tilde{\alpha}^{\prime}\right)\right]-\left[\mathrm{P}(\mathrm{e}(\hat{\alpha})) \Delta_{x}-\mathrm{e}(\hat{\alpha})\right]
$$

where $\tilde{\alpha}^{\prime}=\max \left\langle\alpha^{*}, \tilde{\alpha}\right\rangle$ is the manager's profit share under an optimal managerial contract when value diversion is permitted. This difference gets smaller (equivalently, more negative) as $\bar{\alpha}^{\prime}$ shrinks, which will occur with a rise in $\theta \mathrm{X}$.

\section{ADDITIONAL EFFECTS OF PERMITTING VALUE DIVERSION}

In the model developed in section I, value diversion was assumed to represent a pure wealth transfer from shareholders to managers. This assumption permits us to highlight a cost of value diversion that we wish to emphasize: its effects (in a principal-agent framework) on managerial compensation and, as a consequence, managerial incentives. In this section we address the possibility that value diversion may have additional effects on value. We consider two examples of such effects: first, value diversion may produce benefits for managers that exceed or fall short of the direct costs to shareholders; and second, value diversion may affect 
managers' incentives to exert effort on behalf of the firm. ${ }^{3}$ In light of the cost of value diversion identified in section $I$, these additional effects of diversion must be positive in sign and of sufficient magnitude if permitting value diversion is to enhance ex ante share value. Indeed, we show that in some cases value diversion will reduce ex ante share value regardless of the magnitude of any countervailing positive effects.

\section{A. Managerial Benefits of Value Diversion Differ from Shareholders' Costs}

In some settings, value diversion may produce benefits to managers that either exceed or fall short of the direct costs of such behavior to shareholders. For example, Easterbrook and Fischel (1982: 706-07) argue that permitting managers to take business opportunities of the firm may enhance the value of such opportunities because their value is higher in managers' hands than in the hands of shareholders. To analyze such scenarios, we modify the model of section I by assuming that the benefits of value diversion to managers are $\mathrm{X}+\mathrm{M}$ rather than $\mathrm{X}$, where $\mathrm{M}$ (the difference between the benefits to managers and the direct costs to shareholders) may be positive or negative. (X continues to represent the direct costs of value diversion to shareholders.) We show that permitting value diversion reduces ex ante share value unless $\mathrm{M}$ is positive and exceeds a threshold level identified by our analysis. We also show that permitting value diversion reduces ex ante share value regardless of the sign and magnitude of $\mathrm{M}$ if the manager is paid more than the reservation wage $\mathrm{W}$ to induce managerial effort when value diversion is prohibited.

\footnotetext{
Talley (1998) considers another possibility: that value diversion -- specifically, the taking of corporate opportunities -- may occur against the backdrop of informational asymmetries between managers and shareholders about the profitability of such opportunities. Talley employs a "hidden information" model (in contrast to our "hidden action" model, which emphasizes the standard problem of managerial incentives to exert effort) to analyze such scenarios. Talley's analysis, like ours, suggests that legal restrictions on the taking of corporate opportunities may be desirable.
} 


\section{Participation Constraint Is Binding When Value Diversion Is Prohibited}

We begin by considering the case in which the manager is not paid more than the reservation wage when value diversion is prohibited; the managerial participation constraint binds under an optimal managerial contract. This case corresponds to cases 1 and 2 in the proof of Proposition $1\left(\alpha^{*}<\hat{\alpha}\right)$.

Proposition 3. If the managerial participation constraint binds under an optimal managerial contract when value diversion is prohibited, then permitting value diversion reduces ex ante share value if the difference $M$ between the benefits of such behavior to the manager and the direct costs of the behavior to shareholders satisfies

$$
\mathrm{M}<\left\{\left[\mathrm{P}(\mathrm{e}(\hat{\alpha})) \Delta_{x}-\mathrm{e}(\hat{\alpha})\right]-\left[\mathrm{P}\left(\mathrm{e}\left(\tilde{\alpha}^{\prime}\right)\right) \Delta_{\pi}-\mathrm{e}\left(\tilde{\alpha}^{\prime}\right)\right]\right\} / \theta
$$

where $\bar{\alpha}^{\prime}=\max \left\langle\alpha^{*}, \tilde{\alpha}\right\rangle$.

Proof. Since the managerial participation constraint binds under an optimal managerial contract when value diversion is prohibited, the manager's profit share is $\alpha=\hat{\alpha}$, and ex ante share value is $\underline{\pi}+\mathrm{P}(\mathrm{e}(\hat{\alpha})) \Delta_{\pi}-\mathrm{W}-\mathrm{e}(\hat{\alpha})$, in that circumstance. Meanwhile, when value diversion is permitted, the manager's profit share is $\alpha=\bar{\alpha}^{\prime}$, and ex ante share value is less than or equal to $\underline{\pi}+\mathrm{P}\left(\mathrm{e}\left(\tilde{\alpha}^{\prime}\right)\right) \Delta_{\pi}-\mathrm{W}-\mathrm{e}\left(\tilde{\alpha}^{\prime}\right)+\theta \mathrm{M}$. Therefore, a sufficient condition for lower ex ante share value when value diversion is permitted than when it is prohibited is

$$
\mathrm{P}\left(\mathrm{e}\left(\tilde{\alpha}^{\prime}\right)\right) \Delta_{\pi}-\mathrm{e}\left(\tilde{\alpha}^{\prime}\right)+\theta \mathrm{M}<\mathrm{P}(\mathrm{e}(\hat{\alpha})) \Delta_{\pi}-\mathrm{e}(\hat{\alpha}) .
$$

Rearranging this inequality yields the condition in (5).

Remark. The intuition for this result is as follows. If the managerial participation constrair: binds under an optimal managerial contract when value diversion is prohibited, then moving to 
an environment in which such behavior is permitted induces shareholders to reduce the degree of managerial profit sharing (measured by $\alpha$ ) to either $\alpha^{*}$ or $\bar{\alpha}$. This reduction drives managerial effort further away from the first best level $\mathrm{e}^{\mathrm{FB}}$. If the cost of the reduction in effort exceeds the gain to the shareholder-manager unit from permitting value diversion (given by $\theta \mathrm{M}$ ), then ex ante share value will necessarily fall. The condition that the cost of the reduction in effort exceed the gain from permitting value diversion is precisely the condition in (5). This condition is sufficient (although not necessary) for a fall in ex ante share value. Since $\hat{\alpha}>\bar{\alpha}^{\prime}$, the righthand side of (5) is positive, implying that $\mathrm{M}$ must be not only positive but also sufficiently large in magnitude to outweigh the cost of permitting value diversion that we identify.

\section{Participation Constraint Is Not Binding When Value Diversion Is Prohibited}

We now consider the case in which the managerial participation constraint does not bind under an optimal managerial contract when value diversion is prohibited. Here the manager is paid more than the reservation wage to induce managerial effort. This case corresponds to case 3 in the proof of Proposition 1.

Proposition 4. If the managerial participation constraint does not bind under an optimal managerial contract when value diversion is prohibited, then permitting value diversion always reduces ex ante share value.

Proof. If the managerial participation constraint does not bind under an optimal managerial contract when value diversion is prohibited, then the manager's profit share when value diversion is prohibited is $\alpha=\alpha^{*}$, which implies $\alpha^{*} \geq \hat{\alpha}$ and, hence, $\alpha^{*}>\bar{\alpha}$. The manager's profit share under an optimal managerial contract when value diversion is permitted is therefore 
$\alpha=\alpha^{*}$ as well. The difference in ex ante share value between the environment in which value diversion is permitted and the environment in which it is prohibited is thus $-\theta \mathrm{X}$, which is always negative.

Remark. Intuitively, when managers are paid more than their reservation wage to induce them to exert effort on shareholders' behalf, permitting value diversion causes no adjustment in their direct compensation. Ex ante share value therefore falls by the full expected transfer $\theta \mathrm{X}$, regardless of the existence or magnitude of any benefits from value diversion.

\section{B. Interaction Between Value Diversion and Productive Activity}

The preceding subsection showed that value diversion may reduce ex ante share value even when the direct costs of the behavior to shareholders are less than its benefits to managers. Another potential effect of value diversion is its effect on managerial incentives to engage in productive activity. Value diversion may affect these incentives not only indirectly through its effect on the optimal managerial contract (our focus in section I), but also directly. One possibility is that diversion may encourage managers to exert higher levels of effort on behalf of the firm -- for example, by finding and taking on new projects that enhance firm value. ${ }^{+}$ Diversion would have this effect if the amount of the firm's profit that managers could divert were an increasing function of their effort level: $X=X(e)$ in our model, with $X^{\prime}>0$. Another possibility is that diversion encourages managers to exert less effort on behalf of the firm; this would occur if productive activity and value diversion represented competing pressures on managers' time. Clearly, in this latter case, permitting value diversion would reduce ex ante

\footnotetext{
4 We thank Tracy Lewis and an anonymous referee for suggesting this point to us.
} 
share value, for not only would it produce the effect identified in section I, but also it would result in managers' having a direct incentive to reduce effort (in order to increase the amount of value diverted from the firm).

With $\mathrm{X}^{\prime}(\mathrm{e})>0$, permitting value diversion may either decrease or increase ex ante share value. Intuitively, permitting diversion substitutes compensation though the value-diverting activity for compensation through conventional modes of incentive pay. Since compensation through the value-diverting activity -- like compensation through conventional modes of incentive pay -- encourages managerial effort, the critical question becomes which device is a more effective means of encouraging effort. If conventional incentive compensation is more effective, then permitting value diversion will tend to decrease ex ante share value, whereas if compensation through the value-diverting activity is more effective, then permitting that activity will tend to increase ex ante share value. ${ }^{5}$ The first of these scenarios is most likely if $\mathrm{X}^{\prime}$ (which measures the degree of relationship between effort level and value diversion) is small and $\mathrm{P}^{\prime}$ (which measures the degree of relationship between effort level and the firm's profit) is large; the second is most likely if $\mathrm{X}^{\prime}$ is large and $\mathrm{P}^{\prime}$ is small.

To examine these effects formally, we consider the case examined in Proposition 3 above, in which the managerial participation constraint binds under an optimal managerial

\footnotetext{
5 The case in which compensation through the value-diverting activity is a more effective means of encouraging effort than compensation through conventional incentive pay is related to the analysis of Noe (1997). In Noe's model, a controlling shareholder contracts with a manager in a principal-agent setting; value diversion in the form of insider trading is a possibility. Noe shows that it may be in the controlling shareholder's interest to permit insider trading, for two reasons. First, "managerial payoffs from insider trading are not necessarily paid by the controlling shareholder . . . . Rather they may come at the expense of uninformed liquidity traders submitting orders based on portfolio diversification considerations" (1997: 290). Because we focus on the wealth. of shareholders as a group rather than the wealth of a controlling shareholder, this sort of argument would seem: not to apply to our analysis. Second, Noe finds that there is an incentive for substitution of compensation through. insider trading profits for compensation through conventional incentive pay because the former is a "cheaper" wa: of compensating the manager; this argument seems very similar to our suggestion that if compensation through the value-diverting activity is more effective than compensation through traditional incentive pay in encouraging managerial effort, then permitting value diversion may enhance share value.
} 
contract when value diversion is prohibited. When value diversion is permitted, the contract design problem with $\mathrm{X}=\mathrm{X}(\mathrm{e})$ is given by (3) (substituting $\mathrm{X}(\mathrm{e})$ for $\mathrm{X}$ ). The optimal managerial share $\alpha$ when value diversion is permitted will be between 0 and 1 if (i) $\mathrm{X}^{\prime}(\mathrm{e})<1 / \theta$ for all e; and (ii) $\mathrm{X}^{\prime \prime}$ satisfies the conditions imposed on $\mathrm{P}^{\prime \prime}$ (see section I.A). With $\alpha>0$, the incentive compatibility constraint for the manager may be written as $\mathrm{e}=\underline{\mathrm{e}}(\alpha)$, where $\underline{\mathrm{e}}(\alpha)$ is defined by the first-order condition

$$
\mathrm{P}^{\prime}(\underline{\mathrm{e}}(\alpha)) \alpha \Delta_{x}+\theta \mathrm{X}^{\prime}(\underline{\mathrm{e}}(\alpha))-1=0 \text {. }
$$

The contract design problem when value diversion is permitted thus reduces to the problem of maximizing ex ante share value subject to participation and minimum wealth constraints, all with $\mathrm{e}=\mathrm{e}(\alpha)$. By reasoning analogous to that in sections I.B and I.C, an optimal managerial contract in this setting must have $\mathrm{S}=\mathrm{S}_{0}$, and in turn the optimal managerial share $\alpha$ is given by

$$
\left\{\begin{array}{ll}
\underline{\alpha}^{*} & \text { if } \underline{\alpha}^{*} \geq \tilde{\alpha} \\
\underline{\tilde{\alpha}} & \text { otherwise }
\end{array}\right\},
$$

where $\underline{\alpha}^{*}$ is the unconstrained maximand of the objective function in the contract design problem when value diversion is permitted, and $\underline{\alpha}$ is the minimum profit share permitted by the managerial participation constraint (with $\mathrm{e}=\underline{\mathrm{e}}(\alpha)$ and $\mathrm{S}=\mathrm{S}_{0}$ ) when value diversion is permitted:

$$
\underline{\bar{\alpha}}=\text { minimum } \alpha(\geq 0) \text { such that } \mathrm{S}_{0}+\mathrm{P}(\underline{\mathrm{e}}(\alpha)) \alpha \Delta_{\pi}-\underline{\mathrm{e}}(\alpha)+\theta \mathrm{X}(\underline{\mathrm{e}}(\alpha)) \geq \mathrm{W} \text {. }
$$

( $\underline{\alpha}^{*}$ and $\tilde{\alpha}$ are simply the counterparts (for $\mathrm{X}=\mathrm{X}(\mathrm{e})$ ) to $\alpha^{*}$ and $\tilde{\alpha}$ in section I.C.)

The proposition to follow gives a sufficient condition for value diversion to reduce ex ante share value when the managerial participation constraint binds under an optimal manageriai contract when value diversion is prohibited: 
Proposition 5. If the managerial participation constraint binds under an optimal managerial contract when value diversion is prohibited, then permitting value diversion reduces ex ante share value if the function $\mathrm{X}(\mathrm{e})$ satisfies the following condition:

$$
\mathrm{X}^{\prime}(\mathrm{e}(\hat{\alpha}))<\mathrm{P}^{\prime}(\mathrm{e}(\hat{\alpha}))\left(\hat{\alpha}-\underline{\tilde{\alpha}}^{\prime}\right) \Delta_{\pi} / \theta
$$

where $\underline{\tilde{\alpha}}^{\prime}=\max \left\langle\underline{\alpha^{*}}, \underline{\underline{\alpha}}\right\rangle$.

Proof. The optimal managerial contract has $\alpha=\hat{\alpha}$ when value diversion is prohibited (since the managerial participation constraint binds) and $\alpha=\underline{\alpha}^{\prime}$ when value diversion is permitted. Substituting from the managerial participation constraint, ex ante share value is $\underline{\pi}+\mathrm{P}(\mathrm{e}(\hat{\alpha})) \Delta_{\pi}$ $\mathrm{W}-\mathrm{e}(\hat{\alpha})$ when value diversion is prohibited and is less than or equal to $\underline{\pi}+\mathrm{P}\left(\underline{\underline{e}}\left(\underline{\alpha}^{\prime}\right)\right) \Delta_{\pi}-\mathrm{W}-$ $\underline{\mathrm{e}}\left(\underline{\underline{\alpha}}^{\prime}\right)$ when value diversion is permitted. Therefore, the change in ex ante share value with a move from forbidding to permitting value diversion is less than or equal to

$$
\left[\mathrm{P}\left(\underline{\mathrm{e}}\left(\underline{\tilde{\alpha}}^{\prime}\right)\right) \Delta_{\pi}-\underline{\mathrm{e}}\left(\tilde{\underline{\alpha}}^{\prime}\right)\right]-\left[\mathrm{P}(\mathrm{e}(\hat{\alpha})) \Delta_{\pi}-\mathrm{e}(\hat{\alpha})\right] .
$$

This expression will be negative if $\underline{\mathrm{e}}\left(\underline{\underline{\alpha}}^{\prime}\right)<\mathrm{e}(\hat{\alpha})$, since $\mathrm{d}\left(\mathrm{P}(\mathrm{e}) \Delta_{\pi}-\mathrm{e}\right) / \mathrm{de}>0$ for $\mathrm{e}<\mathrm{e}^{\mathrm{fB}}$ (where $\mathrm{e}^{\mathrm{FB}}$ is the first-best effort level defined above) $\mathrm{e}(\hat{\alpha})<\mathrm{e}^{\mathrm{FB}}$ (as $\left.\hat{\alpha}<1\right) ;$ and $\underline{\mathrm{e}}\left(\underline{\underline{\alpha}}^{\prime}\right)<\mathrm{e}^{\mathrm{FB}}$ (as $\underline{\mathrm{e}}\left(\underline{\tilde{\alpha}}^{\prime}\right)$ $<\mathrm{e}(\hat{\alpha})$ by the condition just imposed). The condition that $\underline{\mathrm{e}}\left(\underline{\underline{\alpha}}^{\prime}\right)<\mathrm{e}(\hat{\alpha})$ in turn will hold if the derivative of the manager's objective function when value diversion is permitted is negative at $\mathrm{e}=\mathrm{e}(\hat{\alpha})$ (meaning that $\underline{\mathrm{e}}\left(\underline{\tilde{\alpha}}^{\prime}\right)$ must be less than $\left.\mathrm{e}(\hat{\alpha})\right)$ :

$$
\mathrm{P}^{\prime}(\mathrm{e}(\hat{\alpha})) \underline{\tilde{\alpha}}^{\prime} \Delta_{x}+\theta \mathrm{X}^{\prime}(\mathrm{e}(\hat{\alpha}))-1<0 .
$$

Substituting using the first-order condition for the manager when value diversion is forbidden $\left(\mathrm{P}^{\prime}(\mathrm{e}(\hat{\alpha})) \hat{\alpha} \Delta_{\tau}=1\right)$ and rearranging terms yields the condition in (6).

Remark. The intuition for the result in Proposition 5 is that when $\mathrm{X}^{\prime}$ is small and $\mathrm{P}^{\prime}$ is large, 
conventional incentive compensation tends to be a more effective means of encouraging managerial effort than compensation through the value-diverting activity. Thus, permitting value diversion in this circumstance will result in the substitution of a less effective means of encouraging effort for a more effective means of doing so. As a consequence, ex ante share value will tend to fall if value diversion is permitted rather than prohibited.

Note that if $\underline{\alpha}^{*}<\underline{\alpha}$, so that the manager's share $\underline{\alpha}^{\prime}$ under the optimal managerial contract when value diversion is permitted is $\underline{\tilde{\alpha}}$, then the right-hand side of (6) is necessarily positive. This is so because a smaller managerial share $\alpha$ is necessary to satisfy the managerial participation constraint when value diversion is permitted than when it is prohibited: $\underline{\alpha}<\hat{\alpha}$. If, however, $\underline{\alpha} \geq \underline{\alpha}$, so that the manager's share under the optimal managerial contract when value diversion is permitted is $\underline{\alpha}^{*}$, then the right-hand side of (6) will be positive if and only if $\underline{\alpha}^{*}<\hat{\alpha}$.

\section{CONCLUSION}

A common view in the law and economics literature is that managerial benefits from value diversion will be offset by reductions in direct compensation, leaving total managerial pay and the total wealth enjoyed by shareholders unchanged. We question this view. Our analysis has shown that within the standard principal-agent framework, permitting value diversion imposes a cost on shareholders that may reduce ex ante share value. For value diversion nonetheless to increase ex ante share value, the countervailing positive effects of such behavior (if any) must be sufficiently large to outweigh the cost we identify. The cost of value diversion emphasized here should be taken into account in designing the legal rules governing this behavior. 


\section{References}

Bebchuk, Lucian Arye. 1989a. "Limiting Contractual Freedom in Corporate Law: The Desirable Constraints on Charter Amendments," 102 Harvard Law Review 1820-1860.

-..--. 1989b. "The Debate on Contractual Freedom in Corporate Law," 89 Columbia Law Review 1395-1415.

------ and Christine Jolls. 1996. "Managerial Value Diversion and Shareholder Wealth," Harvard Law School John M. Olin Center for Law, Economics, and Business, Discussion Paper No. 179.

Brudney, Victor. 1985. "Corporate Governance, Agency Costs, and the Rhetoric of Contract," 85 Columbia Law Review 1403-1444.

Carlton, Dennis W. and Daniel R. Fischel. 1983. "The Regulation of Insider Trading," 35 Stanford Law Review 857-895.

Clark, Robert C. 1986. Corporate Law. Boston: Little, Brown and Co.

Easterbrook, Frank H. and Daniel R. Fischel. 1982. "Corporate Control Transactions," 91 Yale Law Journal 698-737.

-.-.-. 1989. "The Corporate Contract," 89 Columbia Law Review 1416-1448.

------. 1991. The Economic Structure of Corporate Law. Cambridge: Harvard University Press.

Eisenberg, Melvin Aron. 1989. "The Structure of Corporation Law," 89 Columbia Law Review 1461-1525.

Gordon, Jeffrey N. 1989. "The Mandatory Structure of Corporate Law," 89 Columbia Law Review 1549-1598.

Haddock, David D. and Jonathan R. Macey. 1987. "A Coasian Model of Insider Trading," 80 Northwestern University Law Review 1449-1472.

Jolls, Christine. 1995. The Growth of Performance-Based Managerial Pay: Implications for Corporate Finance, Regulatory Policy, and Corporate Governance. Ph.D. dissertation, on file at Dewey Library, M.I.T.

Manne, Henry G. 1966. Insider Trading and the Stock Market. New York: Free Press.

-----. 1970. "Insider Trading and the Law Professors," 23 Vanderbilt Law Review 547-590.

Noe, Thomas H. 1997. "Insider Trading and the Problem of Corporate Agency," 13 Journal of Law, Economics, \& Organization 287-318. 
Scott, Kenneth E. 1980. "Insider Trading: Rule 10b-5, Disclosure and Corporate Privacy," 9 Journal of Legal Studies 801-818.

Talley, Eric. 1998. "Turning Servile Opportunities to Gold: A Strategic Analysis of the Corporate Opportunities Doctrine," Yale Law Journal, forthcoming. 